\title{
Drug use and self-medication among children with respiratory illness or diarrhea in a rural district in Vietnam: a qualitative study
}

This article was published in the following Dove Press journal:

Journal of Multidisciplinary Healthcare

13 September 2011

Number of times this article has been viewed

\author{
Thi Hoan Le ${ }^{1,2}$ \\ Ellinor Ottosson ${ }^{3}$ \\ Thi Kim Chuc Nguyen ${ }^{4}$ \\ Bao Giang Kim ${ }^{5}$ \\ Peter Allebeck' \\ 'Department of Public Health \\ Sciences, Karolinska Institute, \\ Stockholm, Sweden; ${ }^{2}$ Department \\ of Environmental Health, Hanoi \\ Medical University, Hanoi, Vietnam; \\ ${ }^{3}$ Department of Medicine, Gothenburg \\ University, Gothenburg, Sweden; \\ ${ }^{4}$ Department of Family Medicine, \\ Hanoi Medical University, Hanoi, \\ Vietnam; ${ }^{5}$ Department of Health \\ Education, Hanoi Medical University, \\ Hanoi, Vietnam
}

Correspondence: Le Thi Hoan Department of Environmental Health, Hanoi Medical University, Hanoi, Vietnam Tel +84 4912017525

Fax +84 438523032

Email hoan.lethi@gmail.com
Aims: To explore the knowledge, attitudes, and behaviors of parents in their use of drugs for respiratory illness or diarrhea among children under 5 years of age, and to understand factors influencing self-medication.

Methods: A qualitative study was conducted, using in-depth interviews with two drug sellers and three health care providers, and four focus-group discussions with mothers of children under 5 years of age. Verbatim transcriptions were analyzed, and emerging themes and categories identified, using content analysis.

Results: Use of a number of different drugs was reported, including broad-spectrum antibiotics and corticosteroids. There was poor awareness of side-effects, antibiotic resistance, and drug efficacy. Factors influencing self-medication were perceptions of the illness in the child, waiting time, and convenience, the attitudes of public health medical staff, insufficient drug supply in public health facilities, and poor control of prescribed drugs on the market.

Conclusion: Misuse and misconceptions regarding drug use gave rise to considerable problems. Mothers' knowledge and attitudes to illness and health care services played an important role in determining the nature of self-medication. Financial barriers were not the only obstacle to adequate treatment. Health services should be more accessible and responsive to the needs of the population.

Keywords: health services, parental attitudes, education

\section{Introduction}

Self-medication is common in most countries, but use of prescription drugs without contact with professional care providers is a problem largely confined to low- and middle-income countries. ${ }^{1-6}$ Several studies have shown the inappropriate selfmedication of antibiotics for common colds or upper respiratory infections, disorders that are largely self-limiting. ${ }^{7-9}$ It is known that inappropriate self-medication may contribute to antibiotic resistance.

In Vietnam, irrational drug use is widespread. ${ }^{10-12}$ The Vietnamese government has made efforts to eliminate financial barriers to access health care services for the population, and especially for children. Nevertheless, self-medication is still the preferred choice of the majority of the population. Studies of self-medication in different countries have shown that its determinants are a higher educational level, availability of leftover drugs from previous prescriptions, the presence of chronic diseases, less serious ailments, long waiting times, and the need to avoid the cost of a visit to the doctor. ${ }^{4,13-15}$

However, the reasons for self-medication vary between societies, cultures, and types of health services. There are a couple of studies from Vietnam that have tried to explore 
in depth the determinants of self-medication and inappropriate use. ${ }^{11,16}$ Since children are an important target group, in need of appropriate treatment, and because the occurrence of antibiotic resistance must be limited, it is of special interest to understand parents' administration of treatment to their children, which in this paper is regarded as a form of self-medication. Knowledge of drug use and factors influencing self-medication in the population is important for adopting suitable policies. The aim of this study was to explore knowledge, attitudes, and behaviors regarding parents' use of drugs for respiratory or diarrheal illnesses in children less than 5 years of age, and to understand factors influencing self-medication.

\section{Methods}

\section{Study setting}

The study was carried out at a demographic surveillance site called FilaBavi in the Bavi district, which belonged to Ha Tay province at the time of study, ${ }^{17}$ and is located $60 \mathrm{~km}$ north-west of Hanoi. Bavi is a rural district, in which most people rely on agricultural production. The total population of the district is about 235,000. Health services are provided through the public health system, which includes a district hospital in Bavi town, polyclinics, and community health centers, and also by private providers. Health services, including drugs for children less than 5 years of age, are provided free at public health facilities in the district. Although there are pharmacies with qualified staff, drugs are often bought without prescription from drug sellers, who operate unofficially and usually lack qualified or sufficient pharmaceutical training.

\section{Informants and data collection}

A convenience sampling method was adopted for this study. The informants in the focus-group discussions (FGDs) were selected from groups of mothers with children less than 5 years of age in four communes in Bavi district. The average age of these mothers was about 27 years. Knowledge, attitudes, and health behaviors among mothers may vary between economic groups, so participants were selected from both rich and poor households. Socioeconomic conditions were identified on the basis of a local classification. Selection of participants was effected by local supervisors at FilaBavi, who were well acquainted with the district. The selected mothers were informed about the study verbally, and their participation was voluntary. Informants in the in-depth interviews (IDIs) were health care workers, both male and female, at the district hospital, community health stations, and private facilities, and drug sellers at private drugstores and the hospital. They had all worked for about 10 years in the district.

Five IDIs and four FGDs were conducted to gather information about knowledge, attitudes, and behaviors regarding drug use, and reasons for self-medication by parents to their children, who are less than 5 years of age with respiratory illness (RI) or diarrhea.

IDIs were held with two drug sellers and three medical practitioners in both the public and private sectors. IDIs with public professional staff were held at FilaBavi's field office, and IDIs with private professional staff were held at their own facilities.

Four FGDs were held with mothers of children under 5 years of age. The number of informants in the FGDs varied from six to nine, jointly giving a total of 28 . Two of the FGDs involved better-off mothers; the other two, poor mothers. The FGDs were held either in a communal assembly room in the local village or in one of the participants' houses if it was sufficiently large. The authors and two research assistants served as facilitator and note-takers in the FGDs and IDIs. The IDIs and FGDs each lasted about 1.5 hours, and followed a semi-structured interview guide that focused on the attitudes and behaviors of mothers with regard to drug use and self-medication (see Appendix 1).

The procedures for data collection within FilaBavi were approved by the research ethics committees of Hanoi Medical University and Umea University, Sweden.

\section{Data analysis}

The information acquired during the interviews and the FGDs were tape-recorded and transcribed verbatim. The authors listened to the tapes and read through the transcripts to obtain an overview of key contents. Meaning units reflecting the same content were identified, abstracted, and then allocated a code. The codes were sorted into categories related to main themes, according to the procedures of manifest content analysis. ${ }^{18}$ Text analysis was performed by the lead author, together with $\mathrm{KG}$, both of whom have training in qualitative research. The codes identified were discussed and agreed between these two authors.

\section{Results}

Two main themes emerged from the FGDs and IDIs: misconception and misuse of drugs, and factors influencing self-medication. The main themes, their categories, and examples of codes are shown in Table 1. Citations from 
Table I Knowledge, attitudes, and behaviors regarding drug use and self-medication: themes, categories, and a selection of codes

\begin{tabular}{|c|c|c|}
\hline Themes & Categories & Codes \\
\hline \multirow[t]{13}{*}{$\begin{array}{l}\text { Misconception and } \\
\text { misuse of drugs }\end{array}$} & $\begin{array}{l}\text { Common drug use } \\
\text { in cases of RI }\end{array}$ & $\begin{array}{l}\text { Type of drug } \\
\text { use in RI }\end{array}$ \\
\hline & Common drug use & Type of drug \\
\hline & in cases of diarrhea & use in diarrhea \\
\hline & $\begin{array}{l}\text { Inappropriate duration } \\
\text { of treatment }\end{array}$ & $\begin{array}{l}\text { Number of } \\
\text { treatment days }\end{array}$ \\
\hline & & Recovery from illness \\
\hline & Poor dose compliance & Increasing dose \\
\hline & & Decreasing dose \\
\hline & & Flexible dose \\
\hline & Insufficient knowledge & Stunted growth \\
\hline & of effects of drugs & Side-effects \\
\hline & & Antibiotic resistance \\
\hline & Insufficient knowledge & Strong drug \\
\hline & of efficacy of drugs & Weak drug \\
\hline \multirow{20}{*}{$\begin{array}{l}\text { Factors influencing } \\
\text { self-medication }\end{array}$} & Perceptions of the & Minor illness \\
\hline & illness & $\begin{array}{l}\text { Similar to previous } \\
\text { illness }\end{array}$ \\
\hline & & Drug seller's advice \\
\hline & & Previous prescription \\
\hline & Time and convenience & Long waiting time \\
\hline & & Taking the child along \\
\hline & & Near drugstore \\
\hline & & Buy drug at any time \\
\hline & Problems with behaviors & Scold \\
\hline & and attitudes of medical & Grouch \\
\hline & staff & Prescription according \\
\hline & & to guidelines \\
\hline & & Not willing to provide \\
\hline & & drug \\
\hline & Insufficient drug supply & Drug shortage \\
\hline & in public health facilities & Improper drugs \\
\hline & Poor control of & Many types of drugs \\
\hline & prescribed drugs & Variable prices \\
\hline & & Do not need \\
\hline & & prescription \\
\hline
\end{tabular}

participants, from both the FGDs and the IDIs, are presented in italics in the text that follows.

\section{Misconception and misuse of drugs}

Both mothers and health care providers reported that drugs were commonly administered to children with RI or diarrhea. Some mothers did not know which type of drug they had given to their children. They often remembered the color, the shape of the tablet, and the exact price per tablet. Thus, during the discussions, some common drugs used for children with RI or diarrhea were identified.

\section{Common drugs used in cases of RI}

Various combinations of antibiotics, cough and cold preparations, and antipyretics/analgesics, such as paracetamol, were mentioned during the FGDs and IDIs as commonly used drugs for RI. Amoxicillin was often used, and also other antibiotics such as cephalexin and erythromycin. "Amoc [amoxicillin], cough and cold preparations and pred [prednisolone]; every time we use these three types of drugs" (FGD). Other drugs mentioned by mothers, and also by health workers and drug sellers, were:

- Siro, a type of traditional drug used for cough relief;

- Vitamins;

- Babymol, in combination with paracetamol and vitamin B1; and

- Salbutamol, an anti-asthmatic drug.

Prednisolone and dexamethasone, corticosteroids for systemic use, seemed to be a common choice in the case of RI; they were mentioned by mothers even if they were aware of some of the negative effects of these drugs. "Your stomach will be harmed if you take too much dexa [dexamethasone], but it has to be taken to get over the illness" (FGD).

\section{Common drugs used in cases of diarrhea}

In contrast to RI, for treatment of diarrhea, mothers in the FGDs mentioned traditional herbs, eg, tea made from guava leaves. Also, use of various types of antibiotics was frequently mentioned. The antibiotic Biseptol ${ }^{\mathbb{}}$ (Medana Pharma Terpol Group, Sieradz, Poland), a combination of sulfamethoxazole and trimethoprim, seemed to be a commonly used drug for diarrhea. Other drugs, such as Antibio (Han Wha Pharma Co, Yonglin-Si, Kyonggi-Do, Korea), containing Lactobacillus acidophilus, and Smecta ${ }^{\circledR}$ (Beaufour-Ipsen International, Paris, France), an intestinal absorbent, were mentioned. The use of oral rehydration solution was frequently mentioned by health care providers, but rarely by mothers.

\section{Inappropriate duration of treatment}

Mothers in the FGDs reported on the administration of drugs, including antibiotics, for 2 or 3 days, until the child was relieved of symptoms. This was also confirmed by the drug sellers, who had noted that mothers often buy drugs for only 1 or 2 days. "I take drugs for 2 or 3 days; if the child gets better I stop giving the drug. I believe the drugs still have an effect and that the child will recover" (FGD). "I advised that the child should take the drugs for at least 3 days, but in fact many people buy drugs for just 1 day [...] if the child gets better they will stop giving the drug, otherwise they would have bought more" (Drug seller - IDI). 
This situation was also mentioned by a hospital physician: "Mothers give the drug to their child for only 1 or 2 days, and if the child isn't better they want to change to another drug. For example, a child who was hospitalized had already taken two or three different types of drugs over 5 days" (A doctor - IDI).

\section{Poor dose compliance}

Compliance to the dose prescribed by medical staff or recommended by drug sellers was poor. Some mothers said that they tended to increase the dose, so that their child would recover quicker. By contrast, other mothers reported that they tended to decrease the dose because they were concerned about harmful effects on the child. Also, several mothers reported that if they had forgotten to give the child the drug at a certain time, they sometimes compensated for this by giving an extra or a double dose. "I often add 1/2 tablet to the dose in order to help my child recover quickly" (FGD). "Sometimes the pharmacist says 'Give one tablet to your child', but I only give half a tablet [...] I often decrease the dose" (FGD).

\section{Insufficient knowledge of the effects of drugs}

Several misconceptions about drug use were expressed in the FGDs. The mothers thought that the use of drugs can retard their child's growth, but they were not aware of possible adverse effects of the drugs, or of the problem of antibiotic resistance. "My niece got an itch and vomited after having taken antibiotic tablets, but my child has never had any problem after taking a drug" (FGD).

There was a perception that herbal medicine is safer than Western medicine, but also that Western medicines still had to be used. "Flowers and leaves are not harmful, but Western drugs are harmful; they can stunt the growth of the child" (FGD).

\section{Insufficient knowledge of efficacy of drugs} Regarding efficacy of drugs, the mothers tended to share the view that high price and foreign brand implied that a drug was "strong," whereas low price and domestic brand implied a "weak" drug. Some mothers thought that drugs provided by the hospital or by public doctors for outpatients were "weak," whereas drugs sold in private drugstores or by private practitioners were "strong." There was also a perception that "strong" drugs can relieve symptoms quickly. Most mothers thought that injected drugs were "strong," and that a child receiving a "strong" drug would recover more quickly. "Drugs provided by the hospital are weak; if I wanted a strong drug I would buy it in a drugstore outside the hospital. [...] a weak drug costs about 800 dongs for one tablet, a strong drug costs about 2500 dongs for one tablet. [...] severe illness needs strong drugs -foreign drugs; otherwise, you can increase the dose a bit so the child recovers quickly [...]” (FGD).

\section{Factors influencing self-medication Perceptions of illness in the child}

Many mothers reported using self-medication for their child as their first choice when the child fell ill; if the child did not recover, they would seek care at a public health facility. Mothers often practice self-medication when they think the illness is minor at the onset of symptoms, or if the episode is similar to a previous one. Mothers thought that some symptoms, such as coughing or diarrhea, were symptoms of minor illness, whereas some others, including fever, indicated severe illness. Although mothers knew that treatment is free in public health care, they still preferred self-medication to attending a public health facility. "First, I buy drugs myself and give them to my child. If he does not get better, I take him to hospital [...]; this time he got a cough like he had before, so I just bought the same drugs and he recovered. In general, I use one or two doses (days). If my child starts to get better, I continue with the drug; otherwise, I stop and take him to the hospital" (FGD).

In most cases of self-medication, mothers reported having used drugs on the advice of a drug seller or according to a previous prescription. "When my child got sick the first time I took him to hospital. My child took drugs according to a prescription and recovered, so from then onwards, I have just gone out and bought the same drug as before" (FGD). "I went to the drugstore and told the drug seller about my child's illness, and then bought drugs according to the seller's advice. My child recovered, so next time I just went to the drugstore and bought the same as before. I didn't need to take my child for a medical examination" (FGD).

\section{Time and convenience}

Time and convenience were mentioned by many mothers as reasons for self-medication, and for not seeking public professional health care. One particular reason was the long waiting time: "I have to work; visiting the doctor takes all morning, but it takes only a short time to buy a drug. Visiting the doctor would take time away from my job” (FGD). 
Convenience relates to the fact, expressed by the mothers, that drugs were easily bought in the local village, or on returning home after work. Mothers have a problem in finding time to take their children to a health care facility. "I went to a drug seller very near my home, and then spoke about my child's sickness [...]; to go to hospital, I would have had to bring my child along" (FGD).

\section{Problems with the behaviors and attitudes of medical staff}

Several mothers brought up the problem of what they regarded as medical staff's bad attitudes towards citizens. They said that medical staff had scolded them, and were sometimes unwilling to provide drugs. This made them reluctant to visit a doctor at a public health facility in cases of their child's illness, despite the fact that treatment is free. "One time when I took my child to hospital, a doctor said 'Why did you bring your child here with such a minor ailment?'. So, I don't want to go to hospital. I usually get a drug to take at home, and then, if my child does not get better, I have to go to hospital" (FGD). "Medical examinations and drugs for a child are free at the hospital. I only have to pay if I buy a drug outside the hospital ..." (FGD).

Public medical staff reported in the interviews that drugs were prescribed according to treatment guidelines and to a list of recommended drugs, which did not always meet mothers' expectations. Mothers expected that their child should be prescribed more drugs, and also expensive ones. "In public facilities drug prescribing must follow treatment guidelines, so sometimes only one type of drug is prescribed and has a slow observable effect" (A doctor-IDI). "I visited a doctor at the hospital and was only given Bophe (a cough preparation), so I don't want to go to the hospital again" (FGD).

\section{Insufficient drug supply at public health facilities}

Drug shortages and improper drug storage at the community health facilities were reported by mothers during the FGDs. This acted as a disincentive to taking their child to a community health station. "I took my child to the community health station; they said that the subsidized drugs had run out. [...] another time they said that there were no drugs for respiratory infections available, only drugs for diarrhea, but my child didn't have diarrhea. It happened to me three times, going there and going back with nothing. I know of many situations like this, so I hesitate to visit the community health station" (FGD).

\section{Poor control of prescribed drugs}

Drug sellers reported that people could buy antibiotics without a prescription in the district. Many types of antibiotics were sold, including broad spectrum antibiotics such as cephalexin, ampicillin, the macrolides, and the antibiotic combination Erybact $^{\mathbb{B}}$ (Mekophar Co, Ho Chi Minh, Vietnam), which contains erythromycin, trimethoprim, and sulfamethoxazole. In addition, some expensive drugs were sold, such as clamoxin. The price of drugs varied considerably, and some were expensive. Drug sellers also mentioned that smaller amounts were often bought for children, implying short episodes of treatment. Further, drug sellers reported that they often took on the role of physician to advise on customers' drug purchases. "If someone asks me to sell an antibiotic I will sell it, but always from low to high: first common drugs such as amoxicillin or cephalexin, and then rovamixin or clamoxin [...]. I don't offer expensive drugs first, because I'm afraid they don't have enough money. If someone asks for a better drug I will sell the expensive one" (Drug seller - IDI).

\section{Discussion}

\section{Misconception and misuse of drugs}

The FGDs with mothers of children less than 5 years old and the IDIs with health care providers provided similar information on the attitudes and behaviors involved in administering drugs to children with RI or diarrhea.

Antibiotics were used frequently, and also for short periods of time. According to the mothers' accounts, antibiotics were often used even for "minor" illnesses. Okumura et al pointed out in 2002 that antibiotics were regarded in Vietnam as a panacea drug, ${ }^{11}$ and the situation seems to be the same today. Misuse of drugs and antibiotics has been reported previously from Vietnam, ${ }^{16,19}$ and also from other countries, in patients of both low and high income..$^{4,20-23}$

A worrying finding was that mothers reported having experimented with drug dosage and duration of treatment, sometimes abandoning a treatment after 2-3 days. Some mothers increased the dose and others decreased it, on their own. Such misuse of drugs is alarming, since it might increase antibiotic resistance in the district, and more generally in the region and the country. The use of antibiotics for short treatment durations and the purchase of insufficient quantities of drugs have also been reported from other countries. ${ }^{21,24}$

It was observed in this study that mothers had the perception that "strong" drugs often have a foreign brand and a higher price. Mothers thought that drugs provided by public health care facilities were not as "strong" as those bought in drugstores. This is illustrated by the fact that some mothers 
chose to buy even expensive drugs at a drugstore rather than obtaining them free of charge at a public facility.

Use of a combination of antibiotics and corticosteroids was reported by several mothers in cases of RI. This may relate to the idea that "strong" drugs lead to a more rapid recovery. This misconception is certainly one explanation for the frequent use of corticosteroids in the district. Unjustified use of corticosteroids has previously been observed in Vietnam. ${ }^{25}$ The view that "strong" drugs are needed, as well as antibiotics, may prompt the intake of a combination of several drugs. The practice of combining drugs can give rise to side-effects, which have been observed both in Vietnam and in other settings. ${ }^{23,26}$

The misconceptions about and misuse of drugs reported highlight the need for health education and the promotion of awareness about the treatment of common diseases, both among mothers and more generally in the community.

\section{Factors influencing self-medication}

There are several reasons why mothers prefer self-medication for their children, which include perceptions of the illness, time and convenience, the attitudes of public health medical staff, insufficient drug supply in public health facilities, and poor control of prescribed drugs on the market. Mothers reported that time and convenience were factors that influenced self-medication. This is in line with Yousef et al's finding that long waiting time is a factor that influences selfmedication. ${ }^{14}$ Studies have shown that avoiding the cost, or perceived high cost, of visiting a doctor tends to favor selfmedication. ${ }^{14,27}$ Although health care was free at the public health facilities in the study area, people still hesitated to use it. This means that the policy of providing free health care services for children in Vietnam has not yet been successfully implemented.

Providers' behaviors and attitudes have an important role to play in patient satisfaction. ${ }^{28}$ The perceived attitudes of health care providers can act as a barrier to the seeking of care at professional facilities. The differences between mothers' expectations and current treatment guidelines for drug prescription may create a communication barrier between health care providers and patients. Proper communication and a good relationship between health care staff and patients are essential to improve compliance, but the findings of this study indicate that this is an area in which improvement is needed.

The combination of insufficient drugs in public health facilities and their availability in drugstores was found to increase self-medication, a finding that is in line with those of studies conducted in Europe. ${ }^{29}$ The easy availability of potent drugs, including antibiotics, is a prerequisite for extensive improper drug use, and better control of drugs is therefore a high priority in curbing the misuse of drugs, especially of antibiotics, identified in the current study. The situation also reflects the needs for better planning of health services that meet the requirements of the population, and for the better control of prescribed drugs sold on the market. The discrepancy between what is advocated in public health facilities and what is available on the private market indicates a need for better collaboration between the public and the private sectors.

\section{Strengths and limitations}

The validity of data from qualitative studies can always be questioned. In this case, the number of participants was limited, but the validity was strengthened through triangulation. Information was gathered from various sources: mothers, and health care providers in both the public and private health sectors at various levels. This study took advantage of FGDs, which captured interaction between participants, and thereby allowed further exploration of the attitudes and experiences of the mothers. The selection of mothers from different socioeconomic groups enabled a more complete picture of divergent reporting to be obtained, although the reports turned out not to differ substantially between the groups.

While the results of this study may not be considered representative of the community as a whole, due to their qualitative nature, the authors believe the findings indicate problems that confirm and add to previous observations of self-medication in the treatment of children in Vietnam and in other low- and middle-income countries.

\section{Conclusion}

This study suggests that there are considerable misconceptions and misuse with regard to drugs for children less than 5 years old with RI or diarrhea. The study highlights the need for a comprehensive program to improve rational drug use, especially antibiotic use that targets health care providers as well as the general population. Financial barriers are not the only obstacle to adequate treatment. Mothers' knowledge and attitudes towards illness and sources of health care play an important role in self-medication. Health services should be more accessible and responsive to the needs of the population. Better collaboration between private and public health care providers as well as patients should be encouraged. 


\section{Acknowledgments}

The authors are grateful to all the informants, who willingly contributed their knowledge and perceptions, and to FilaBavi's supervisors for their support. The authors especially thank Mr Dao Dinh Sang and Ms Nguyen Minh Trang for their contributions to the study. This study was supported by the Swedish International Development Agency (Sida).

\section{Disclosure}

The authors report no conflicts of interest in this work.

\section{References}

1. Pereira FS, Bucaretchi F, Stephan C, Cordeiro R. Self-medication in children and adolescents. J Pediatr (Rio J). 2007;83(5):453-458.

2. Ylinen S, Hämeen-Anttila K, Sepponen K, Lindblad AK, Ahonen R. The use of prescription medicines and self-medication among children - a population-based study in Finland. Pharmacoepidemiol Drug Saf. 2010;19(10):1000-1008.

3. Raz R, Edelstein H, Grigoryan L, Haaijer-Ruskamp FM. Self-medication with antibiotics by a population in northern Israel. Isr Med Assoc J. 2005;7(11):722-725.

4. Bi P, Tong S, Parton KA. Family self-medication and antibiotics abuse for children and juveniles in a Chinese city. Soc Sci Med. 2000;50(10): $1445-1450$.

5. Abasaeed A, Vlcek J, Abuelkhair M, Kubena A. Self-medication with antibiotics by the community of Abu Dhabi Emirate, United Arab Emirates. J Infect Dev Ctries. 2009;30(3):491-497.

6. Landers TF, Ferng YH, McLoughlin JW, Barrett AE, Larson E. Antibiotic identification, use, and self-medication for respiratory illnesses among urban Latinos. J Am Acad Nurse Pract. 2010;22(9):488-495.

7. Togoobaatar G, Ikeda N, Ali M, et al. Survey of non-prescribed use of antibiotics for children in an urban community in Mongolia. Bull World Health Organ. 2010;88(12):930-936.

8. Ilhan MN, Durukan E, Ilhan SO, Aksakal FN, Ozkan S, Bumin MA. Self-medication with antibiotics: questionnaire survey among primary care center attendants. Pharmacoepidemiol Drug Saf. 2009;18(12): 1150-1157.

9. Skliros E, Merkouris P, Papazafiropoulou A, et al. Self-medication with antibiotics in rural population in Greece: a cross-sectional multicenter study. BMC Fam Pract. 2010;11:58.

10. Larsson M, Falkenberg T, Dardashti A, et al. Overprescribing of antibiotics to children in rural Vietnam. Scand J Infect Dis. 2005;37(6-7) 442-448.

11. Okumura J, Wakai S, Umenai T. Drug utilisation and self-medication in rural communities in Vietnam. Soc Sci Med. 2002;54(12):1875-1886.

12. Hoan LT, Chuc NTK, Ottosson E, Allebeck P. Drug use among children under 5 with respiratory illness and/or diarrhoea in a rural district of Vietnam. Pharmacoepidemiol Drug Saf. 2009;18(6):448-453.
13. Grigoryan L, Haaijer-Ruskamp FM, Burgerhof JG, et al. Selfmedication with antimicrobial drugs in Europe. Emerg Infect Dis. 2006; 12(3):452-459.

14. Yousef AM, Al-Bakri AG, Bustanji Y, Wazaify M. Self-medication patterns in Amman, Jordan. Pharm World Sci. 2008;30(1):24-30.

15. Shankar P, Partha P, Shenoy N. Self-medication and non-doctor prescription practices in Pokhara valley, Western Nepal: a questionnaire based study. BMC Fam Pract. 2002;3:17.

16. Hoa NQ, Ohman A, Lundborg CS, Chuc NT. Drug use and healthseeking behavior for childhood illness in Vietnam - a qualitative study. Health Policy. 2007;82(3):320-329.

17. Chuc NTK, Diwan VK. FilaBavi, a demographical surveilance site, an epidemiological field laboratory in Vietnam. Scan J Public Health. 2003;3(Suppl 62):3-7.

18. Graneheim UH, Lundman B. Qualitative content analysis in nursing research: concepts, procedures and measures to achieve trustworthiness Nurse Educ Today. 2004;24(2):105-112.

19. Larsson M, Kronvall G, Chuc NT, et al. Antibiotic medication and bacterial resistance to antibiotics: a survey of children in a Vietnamese community. Trop Med Int Health. 2000;5(10):711-721.

20. Väänänen $M H$, Pietilä K, Airaksinen M. Self-medication with antibiotics - does it really happen in Europe? Health Policy. 2006;77(2): 166-177.

21. Calva J, Bojalil R. Antibiotic use in a periurban community in Mexico: a household and drugstore survey. Soc Sci Med. 1996;42(8): $1121-1128$

22. Kristiansson C, Reilly M, Gotuzzo E, et al. Antibiotic use and healthseeking behaviour in an underprivileged area of Peru. Trop Med Int Health. 2008;13(3):434-441.

23. Chanin Chareonkul VLK, Chaweewon Boonshuyar. Rational drug use in Cambodia: study of three pilot health centers in Kampong Thom Province. Southeast Asian J Trop Med Public Health. 2002;33(2): 418-424.

24. Chuc NT, Larsson M, Falkenberg T, Do NT, Binh NTa, Tomson GB. Management of childhood acute respiratory infections at private pharmacies in Vietnam. Ann Pharmacother. 2001;35(10):1283-1288.

25. Chuc NT, Tomson G. "Doi moi" and private pharmacies: a case study on dispensing and financial issues in Hanoi, Vietnam. Eur J Clin Pharmacol. 1999;55(4):325-332.

26. Siddiqi $\mathrm{S}$, Hamid $\mathrm{S}$, Rafique $\mathrm{G}$, et al. Prescription practices of public and private health care providers in Attock district of Pakistan. Int $J$ Health Plann Manage. 2002;17(1):23-40.

27. Amaghionyeodiwe LA. Determinants of the choice of health care provider in Nigeria. Health Care Manag Sci. 2008;11(3):215-227.

28. Mendoza Aldana J, Piechulek H, al-Sabir A. Client satisfaction and quality of health care in rural Bangladesh. Bull World Health Organ. 2001;79(6):512-517.

29. Grigoryan L, Burgerhof JG, Degener JE, et al. Determinants of self-medication with antibiotics in Europe: the impact of beliefs, country wealth and the healthcare system. JAntimicrob Chemother. 2008;61(5): $1172-1179$. 


\section{Appendix}

Appendix I Interview guide for the focus-group discussions

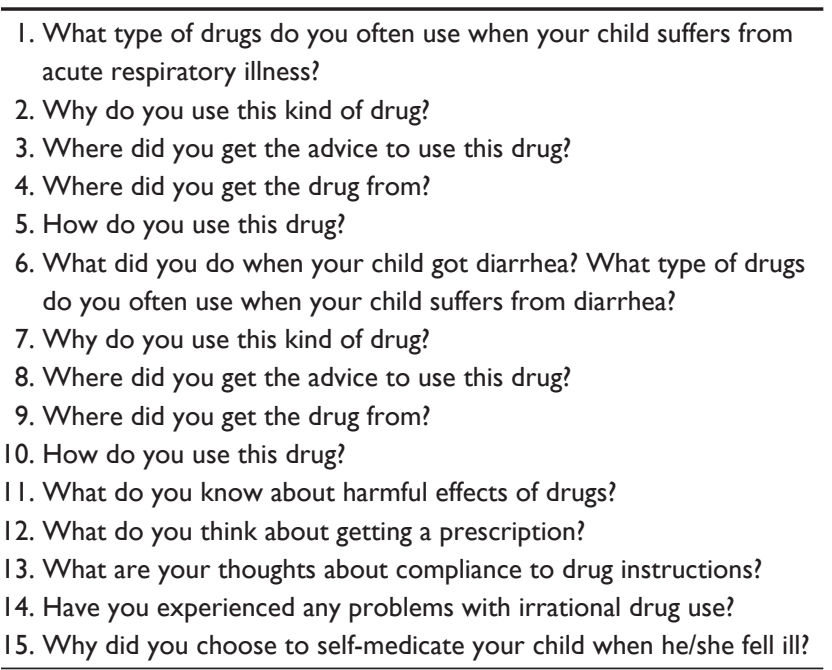

\section{Publish your work in this journal}

The Journal of Multidisciplinary Healthcare is an international, peerreviewed open-access journal that aims to represent and publish research in healthcare areas delivered by practitioners of different disciplines. This includes studies and reviews conducted by multidisciplinary teams as well as research which evaluates the results or conduct of such teams or healthcare processes in general. The journal covers a wide range of areas and welcomes submission from practitioners at all levels, from all over the world. The manuscript management system is completely online and includes a very quick and fair peer-review system. Visit http://www.dovepress.com/testimonials.php to read real quotes from published authors.

Submit your manuscript here: http://www.dovepress.com/journal-of-multidisciplinary-healthcare-journal 